\title{
Integrating the National Biosafety Guidelines in the East African Community
}

\section{Miruka Conrad Ondieki*}

Kampala International University-Western Campus, P.O. BOX 71, Bushenyi, Uganda

\section{Editorial}

The East African Community (EAC), an inter-governmental organization which came into full force in July 2000, was established under Article 2 of the Treaty for the Establishment of the East African Community. The community comprises five partner countries namely Republics of Burundi, Kenya, Rwanda, Uganda and the United Republic of Tanzania. Each of the partner states has its own guidelines and policies concerning biosafety. Among other things that the community targets to achieve in the period ending 2015/2016, is the establishment of regional institutional frameworks.

By the year 2008, a total of 143 countries had become signatories to the Cartagena protocol on biosafety. The biosafety frameworks of all member states in the community have several common features, which include administrative systems, institutional arrangements, public awareness, legal frameworks and regulatory regimes, socio-economic considerations among others [1].

While many of the features of the guidelines of EAC member states on biosafety are similar, the intricate details therein reveal a very wide gap in how specific aspects are perceived. For instance, the Burundian guidelines for public awareness and education on biosafety tend to focus more on things to do with the environment, leaving out the actual area of biosafety [2]. Even though biosafety should include considerations towards the environment, it is clearly discernible that the aspects of environment focused on in the Burundian document are far out of what it supposed to be. The Tanzanian version, in its section on public awareness and education, acknowledges that the level of public awareness on biotechnology and biosafety in the country is extremely low. Due to this low level of awareness in Tanzania, there is occasional under-reporting and distorted reporting by the public and private media in the country $[1,3]$. It is noteworthy to point out that the proposed mechanisms for public awareness and education stipulated in the Rwandan version of the guidelines are indeed commendable [4]. Of particular importance is a mechanism which will ensure that information will reach all members of the Rwandan public (through the use of an appropriate language)? Likewise the Kenyan system on biosafety has been faulted for not intensifying its public awareness and education campaigns [5]. In its biosafety guidelines, the section that touches on public awareness and education does highlight the relatively low level of awareness by the public about biotechnology and biosafety.

One major concern with the implementation of biosafety guidelines in the EAC member states is that all of them are underequipped in their technical capacities to carry out biotechnology and therefore biosafety activities. As some member states make progress in building their capacity to handle biosafety issues, other member states lag behind in the same aspect. This can make future integration of the guidelines a complex task to achieve.

Another sort of impediment that can lie in the way of regional integration is the reluctance to accept genetically modified organisms (GMOs) in member states. Some countries for instance do not allow GMOs into their territories, even for research purposes. How will such countries accept to share the same platform of regulations with another or others that allow such organisms into their territories? It therefore remains to be seen whether, as it seeks more integration of its activities, the East African Community will integrate the national guidelines on biosafety.

\section{References}

1. Mtui G (2012) Biosafety systems in Eastern and Central Africa. African Journa of Environmental Science and Technology 6: 80-93.

2. National biosafety framework in Burundi (2006) Ministry of urban planning, tourism and environment. Republic of Burundi. Bujumbura.

3. The National Biosafety Framework for Tanzania (2004) Division of Environment, Vice President's Office. United Republic of Tanzania. Dar es Salaam.

4. The National Biosafety Framework for Rwanda (2005) Ministry of Lands Environment, Forestry, Water and Mines. Republic of Rwanda. Kigali.

5. Kingiri A, Ayele $S$ (2009) Towards a smart biosafety regulation: The case of Kenya. Environ Biosafety Res 8: 133-139.
*Corresponding author: Miruka Conrad Ondieki, Kampala International UniversityWestern Campus, P.O. BOX 71, Bushenyi, Uganda, Tel: +256777410403; E-mail: conradmiruka@yahoo.com

Received December 20, 2014; Accepted December 22, 2014; Published December 24, 2014

Citation: Ondieki MC (2014) Integrating the National Biosafety Guidelines in the East African Community. J Biosafety Health Educ 2: e118 doi:10.4172/2332 $0893.1000 \mathrm{e} 118$

Copyright: (c) 2014 Ondieki MC. This is an open-access article distributed unde the terms of the Creative Commons Attribution License, which permits unrestricted use, distribution, and reproduction in any medium, provided the original author and source are credited. 